\title{
Role of the initial degree of anaemia and treatment model in the prognosis of gastric cancer patients treated by chemotherapy: a retrospective analysis
}

\author{
Wen-Huan Li ${ }^{1 *}$ (D) Ji-Yu Zhang ${ }^{2}$, Wen-Hui Liu ${ }^{3}$ and Xian-Xian Chen²
}

\begin{abstract}
Background: Anaemia is highly prevalent in gastric cancer (GC) patients. The role of initial haemoglobin levels in predicting the prognosis of GC patients treated by chemotherapy has not been well determined. Our present study aims to evaluate the relationship between the degree of anaemia and the overall survival (OS) and progression-free survival (PFS) of patients with GC.

Methods: Our retrospective study enrolled 598 patients who were treated with chemotherapy when the recurrent or metastatic GCs were unsuitable for surgical resection. Univariate and multivariate analyses were performed to identify risk factors that had the potential to affect patient prognosis. Additionally, the relationship between clinicopathological characteristics, including treatment method, and degree of cancer-related reduction in haemoglobin was further analysed.

Results: Our results revealed that patients with $\mathrm{HB}_{\text {ini }}$ level $\leq 80 \mathrm{~g} / \mathrm{L}$ had a trend toward a shortened median OS and PFS ( $p=0.009$ and $p=0.049$, respectively). Interestingly, we also found that $\mathrm{HB}_{\mathrm{dec}} \geq 30 \mathrm{~g} / \mathrm{L}$ was associated with a significantly shortened median OS and PFS ( $p=0.039$ and $p=0.001$, respectively). Multivariate analysis showed that $H B_{\text {ini }}$ levels $\leq 80 \mathrm{~g} / \mathrm{L}$ could be used as an independent prognostic factor for recurrent and metastatic GC. More importantly, $\mathrm{HB}_{\mathrm{dec}} \geq 30 \mathrm{~g} / \mathrm{L}$ and treatment response were also significantly associated with OS and PFS.

Furthermore, the degree of haemoglobin decrease was associated with chemotherapy including platinum and the number of chemotherapy cycles.

Conclusion: Our study concludes that the initial degree of anaemia and a decrease in haemoglobin of $\geq 30 \mathrm{~g} / \mathrm{L}$ can serve as biomarkers to predict prognosis in recurrent or metastatic GC patients, while chemotherapy treatment rather than red blood cell (RBC) transfusion can improve their prognosis. Additionally, platinum should not be recommended for treating severely anaemic GC patients.
\end{abstract}

Keywords: Anaemia, Gastric cancer, Chemotherapy, Prognosis, Decrease in haemoglobin

\footnotetext{
*Correspondence: m15168863879@163.com; liwenhuan0906@outlook.com; xianchen681@163.com

'Department of Oncology, Shandong Provincial Hospital Affiliated to

Shandong University, 324 Jingwu RD, Jinan 250021, Shandong, People's

Republic of China

${ }^{2}$ Shandong Center for Diseases Control and Prevention, 16992 Jingshi RD,

Jinan 250014, Shandong, People's Republic of China

Full list of author information is available at the end of the article
}

(C) The Author(s). 2020 Open Access This article is licensed under a Creative Commons Attribution 4.0 International License, which permits use, sharing, adaptation, distribution and reproduction in any medium or format, as long as you give appropriate credit to the original author(s) and the source, provide a link to the Creative Commons licence, and indicate if changes were made. The images or other third party material in this article are included in the article's Creative Commons. licence, unless indicated otherwise in a credit line to the material. If material is not included in the article's Creative Commons licence and your intended use is not permitted by statutory regulation or exceeds the permitted use, you will need to obtain permission directly from the copyright holder. To view a copy of this licence, visit http://creativecommons.org/licenses/by/4.0/ The Creative Commons Public Domain Dedication waiver (http://creativecommons.org/publicdomain/zero/1.0/) applies to the data made available in this article, unless otherwise stated in a credit line to the data. 


\section{Background}

Gastric cancer (GC) is the fifth most common malignant tumour and the third leading cause of death worldwide [1]. Recurrence and metastasis are the most important characteristics of cancers including GC [2,3]. The incidence of anaemia in advanced gastric cancer patients is high, with a large variability ranging from 10 to $30 \%[4,5]$. Anaemia can weaken the fragile patient and has been reported to be associated with a poor clinical outcome. However, the role of the degree of anaemia and treatment model in recurrent or metastatic GC patient prognosis is unclear. Therefore, managing and improving the condition of GC-related anaemia through medical approaches are urgently needed to improve the prognosis of patients with recurrent or metastatic GC.

Cancer-related anaemia (CRA) is considered to be associated with multiple pathological and clinical factors, such as bleeding, nutritional deficiency, and bone marrow suppression [6]. Bone marrow suppression can be caused by both malignant cell infiltration and chemotherapy treatment $[7,8]$. Functional iron deficiency is usually associated with insufficient iron intake because of cancer-related appetite loss and bleeding [9, 10]. At present, the treatments of anaemia and cancer are complementary. Under these circumstances, it is critical to identify the association of relevant elements, including clinicopathological characteristics and GC treatment model, with anaemia in recurrent or metastatic GC.

Our study aimed to determine the role of initial degree of anaemia and cancer-related haemoglobin reduction in the prognosis of recurrent or metastatic GC patients. The relationships between clinicopathological characteristics, including treatment regimens, and cancer-related haemoglobin reduction degree were further analysed. Our study will contribute to the determination of treatment approaches for recurrent or metastatic GC-related anaemia patients.

\section{Methods \\ Patients}

All procedures followed were in accordance with the ethical standards of the ethical committee of Shandong Provincial Hospital regarding human experimentation and with the 1964 Helsinki Declaration and later versions. Informed consent for inclusion in the study was obtained from all patients.

Our retrospective study analysed the data collected from patients diagnosed with metastatic GC or recurrent GC at Shandong Provincial Hospital in China from January 1,2010 , to December 31,2014 . The entry criteria included the following: 1) metastatic GC or recurrent GC after radical surgical treatment was histologically confirmed as gastric adenocarcinoma - radical gastric resection was defined as negative margins, en bloc resection of the greater and lesser omentum, and D2 lymph node dissection, and standard lymphadenectomy was defined as when the number of retrieved lymph nodes was $\geq 15$; 2) The Eastern Cooperative Oncology Group performance score (ECOG PS) was used to estimate a life expectancy of more than 3 months [11]; and 3) patients had received at least one cycle of chemotherapy. The exclusion criteria included the following: 1) accompaniment by other types of malignancies, 2) use of neoadjuvant chemotherapy, and 3) loss to follow-up. All the pathologic specimens were reviewed by at least 2 pathologists to confirm the diagnosis of GC.

\section{Haemoglobin level measurement}

The initial haemoglobin level $\left(\mathrm{HB}_{\text {ini }}\right)$ was collected at the initial diagnosis of recurrent or metastatic GC. The lowest haemoglobin level was determined as the lowest level obtained from the day of diagnosis to the date of death or the final follow-up visit. The decrease in haemoglobin $\left(\mathrm{HB}_{\mathrm{dec}}\right)$ was defined by subtracting the lowest haemoglobin level from the initial haemoglobin level. Evaluation and grading of anaemia were performed according to $\mathrm{Na}$ tional Comprehensive Cancer Network (NCCN) guidelines for cancer- and chemotherapy-induced anaemia [12].

When the HBini was less than $70 \mathrm{~g} / \mathrm{L}, \mathrm{RBC}$ transfusions were used to improve the anaemia until the initial $\mathrm{Hb}$ was more than $70 \mathrm{~g} / \mathrm{L}$, and the dose of chemotherapeutic drugs was not regulated.

\section{Chemotherapy regimens}

The regimens used to treat the patients included the combination chemotherapy of docetaxel, cisplatin, and 5-fluorouracil (DCF) and related modifications (docetaxel $75 \mathrm{mg} / \mathrm{m}^{2}$ on day 1 , cisplatin $60 \mathrm{mg} / \mathrm{m}^{2}$ or oxaliplatin $130 \mathrm{mg} / \mathrm{m}^{2}$ on day 1 , fluorouracil $2500 \mathrm{mg} / \mathrm{m}^{2}$ continuous infusion $120 \mathrm{~h}$, cycled every 21 days); XP or modifications (capecitabine $1000 \mathrm{mg} / \mathrm{m}^{2}$ twice daily (BID) on days $1-14$, cisplatin $75 \mathrm{mg} / \mathrm{m}^{2}$ or oxaliplatin $130 \mathrm{mg} / \mathrm{m}^{2}$ on day 1); FOLFIRI (irinotecan $180 \mathrm{mg} / \mathrm{m}^{2}$ on day 1 , leucovorin $400 \mathrm{mg} / \mathrm{m}^{2}$ on day 1 , fluorouracil $400 \mathrm{mg} / \mathrm{m}^{2}$ IV push on day 1 , fluorouracil $2400 \mathrm{mg} /$ $\mathrm{m}^{2}$ continuous infusion $46 \mathrm{~h}$, cycled every 14 days); paclitaxel liposome $100 \mathrm{mg} / \mathrm{m}^{2}$ (q2w) or $135-150 \mathrm{mg} /$ $\mathrm{m}^{2}$ (q3w) on day 1 , combine with capecitabine or $\mathrm{S}-1$; and single agents such as docetaxel $75-100 \mathrm{mg} / \mathrm{m}^{2}$ on day 1 , capecitabine $1000-1250 \mathrm{mg} / \mathrm{m}^{2}$ BID on days $1-$ 14 , or S-1 $80-120 \mathrm{mg}$ on days $1-14$, cycled every 21 days. The first line chemotherapy regimens include DCF, Paclitaxel liposome + Capecitabine / S-1 or XP. The second line chemotherapy regimens include FOLFIRI or single agent. The treatment effect of chemotherapy was estimated after 2 cycles of the chemotherapy regimen with 3 weeks or 3 cycles of the chemotherapy regimen with 2 weeks. 


\section{Follow-up}

Tumour responses to the chemotherapy regimens were evaluated after every 2-3 cycles of chemotherapy and categorized based on the Response Evaluation Criteria in Solid Tumors (RECIST) 1.1 guidelines [13]. The number of malignant ascites and peritoneal cytology were also considered when assessing the antitumour effects.

Overall survival (OS) was calculated as the time from the date of initial diagnosis of metastatic GC or the date of recurrence after GC resection to the date of either death or the final follow-up. Progression-free survival (PFS) was calculated as the date of either disease progression, confirmed by magnetic resonance imaging or computed tomography using a contrast medium if possible, or death from any cause.

Clinical variables for risk assessment consisted of patient demographics, surgical and pathological factors, chemotherapy regimens, and packed red cell transfusion. Data regarding recurrence, defined as disease recurrence at any site, and survival outcomes were also collected.

Peritoneal metastasis is a frequent type of metastasis of gastric cancer and is a definitive determinant for prognosis. Peritoneal metastasis was diagnosed by histological diagnosis of peritoneal metastasis and/or by peritoneal lavage cytology positive for cancer cells.

\section{Statistical analysis}

Survival analyses were performed by Kaplan-Meier curves with log-rank tests for significance. Statistical analysis included univariate analysis and multivariate analysis. Univariable Cox regression analyses were performed using PFS, OS and $\mathrm{HB}_{\mathrm{dec}}$ as the outcomes, with a significance level of $p<0.05$. Multivariate analysis was carried out with a Cox proportional hazards model to evaluate prognostic factors with respect to PFS, OS and $\mathrm{HB}_{\mathrm{dec}}$. The factors which were potential risk factors for GC patient's prognosis or having statistical significance from the univariate analysis data were performed in Cox multivariate model. Hazard ratios (HRs) and 95\% confidence intervals (CIs) were calculated. A value of $p<0.05$ was considered statistically significant. All statistical analyses were conducted using SPSS statistical software (Version 24.0; IBM Corporation, Armonk, NY, USA).

\section{Results}

\section{Patients}

Based on the inclusion and exclusion criteria, 598 patients were included in our study. Our study included 170 recurrent GC patients and 428 metastatic GC patients. The general characteristics including the kinds of chemotherapy regimen of all enrolled patients are listed in Table 1. The age and gender proportions and surgical and pathological factors of the patient population were similar to those observed in other studies [14].
There were 312 patients treated with the first line chemotherapy regimens, yet the GC in 188 patients remained in a development condition, and then those patients were treated with the second or/and third line chemotherapy regimens including FOLFIRI and docetaxel single agent. The cycles of chemotherapy used for our GC patients was $4.4 \pm 3.705$ [1-20]. Two hundred eighty six patients $(47.8 \%)$ failed to receive further chemotherapy after 1-2 cycles of chemotherapy treatment.

\section{Follow-up and survival}

Of the 598 GC patients, the median follow-up time was 11.60 months (range 0-76), and the median OS after chemotherapy was 12 months (95\% CI 11.221-12.779), with 1-, 3-, and 5-year OS rates of 45.40, 3.80, and $0.90 \%$, respectively.

The 598 patients were divided into the $\mathrm{HB}_{\text {ini }} \leq 80 \mathrm{~g} / \mathrm{L}$ cohort and the $\mathrm{HB}_{\text {ini }}$ level $>80 \mathrm{~g} / \mathrm{L}$ cohort. Our study included 40 patients in the $\mathrm{HB}_{\text {ini }} \leq 80 \mathrm{~g} / \mathrm{L}$ cohort and 558 patients in the $\mathrm{HB}_{\text {ini }}$ level $>80 \mathrm{~g} / \mathrm{L}$ cohort. The clinical features which have potential effects on GC patient OS and PFS were well matched between our two groups (Table 2).

For the $\mathrm{HB}_{\text {ini }} \leq 80 \mathrm{~g} / \mathrm{L}$ cohort, the median OS was 10 months with 1-, 3-, and 5-year survival rates of 35.40, 0 , and $0 \%$, respectively, while in the $\mathrm{HB}_{\text {ini }}$ level $>80 \mathrm{~g} / \mathrm{L}$ cohort, the median OS was 12 months with 1-, 3-, and 5year survival rates of $46.10,4.10$, and $3.00 \%$, respectively. The OS of the $\mathrm{HB}_{\text {ini }} \leq 80 \mathrm{~g} / \mathrm{L}$ cohort was significantly worse than that of the $\mathrm{HB}_{\text {ini }}$ level $>80 \mathrm{~g} / \mathrm{L}$ cohort $(p=$ 0.009, Fig. 1a, Table 3).

Then, we compared the OS and PFS between the $\mathrm{HB}_{\text {ini }} \leq 80 \mathrm{~g} / \mathrm{L}$ cohort and the cohort with $\mathrm{HB}_{\text {ini }}$ between $80 \mathrm{~g} / \mathrm{L}$ and $110 \mathrm{~g} / \mathrm{L}$. Our results revealed that the $\mathrm{HB}_{\text {ini }} \leq$ $80 \mathrm{~g} / \mathrm{L}$ cohort did not have a trend of worse OS and PFS than the mild anaemia cohort (Supplementary Table 1).

Kaplan-Meier analysis was also used to analyse the correlation between $\mathrm{HB}_{\text {ini }}$ level and PFS. Our results revealed that patients with $\mathrm{HB}_{\text {ini }}$ levels $\leq 80 \mathrm{~g} / \mathrm{L}$ also had a trend toward a shortened median PFS ( $p=0.049$, Fig. $1 b$, Table 3). Interestingly, we also found that $\mathrm{HB}_{\mathrm{dec}} \geq 30 \mathrm{~g} / \mathrm{L}$ was associated with a significantly shortened median OS ( $p=0.039$, Fig. 1c), and a similar relationship was found with decreased median PFS ( $p=0.001$, Fig. $1 d$, Table 3 ).

Red blood cell (RBC) transfusion is an important treatment modality, while chemotherapy is beneficial for improving the prognosis of recurrent and metastatic GC patients. We analysed the different treatment modalities and clinicopathological parameters for the OS and PFS in our patients.

Using univariate analysis, we found that RBC transfusion was associated with neither median OS nor median PFS. The factors that significantly influenced OS were $\mathrm{HB}_{\text {ini }}$ level, $\mathrm{HB}_{\text {ini }} \leq 80 \mathrm{~g} / \mathrm{L}$, metastatic sites $\geq 3$, liver 
Table 1 Patients characteristics

\begin{tabular}{|c|c|c|}
\hline & Total $N=598$ & \\
\hline \multicolumn{3}{|l|}{ Age } \\
\hline$<65$ years, $\mathrm{N}(\%)$ & \multicolumn{2}{|l|}{$230(38.5)$} \\
\hline$\geq 65$ years, $N(\%)$ & \multicolumn{2}{|l|}{$368(61.5)$} \\
\hline \multicolumn{3}{|l|}{ Gender } \\
\hline Male, N (\%) & \multicolumn{2}{|l|}{$469(78.4)$} \\
\hline Female, N (\%) & \multicolumn{2}{|l|}{$129(21.6)$} \\
\hline \multicolumn{3}{|l|}{ Palliative setting } \\
\hline Initially metastatic & \multicolumn{2}{|l|}{ 428(71.6) } \\
\hline Recurrent & \multicolumn{2}{|l|}{$170(28.4)$} \\
\hline \multicolumn{3}{|l|}{ Operation method } \\
\hline Proximal gastrectomy & \multicolumn{2}{|l|}{$60(35.3)$} \\
\hline Distal gastrectomy & \multicolumn{2}{|l|}{$83(48.8)$} \\
\hline Total gastrectomy & \multicolumn{2}{|l|}{$27(15.9)$} \\
\hline \multicolumn{3}{|l|}{ Pathological type } \\
\hline Well differentiated & \multicolumn{2}{|l|}{$4(0.7)$} \\
\hline Moderately differentiated & \multicolumn{2}{|l|}{$59(9.8)$} \\
\hline Poorly differentiated & \multicolumn{2}{|l|}{ 250(41.8) } \\
\hline Signet ring cell & \multicolumn{2}{|l|}{$61(10.2)$} \\
\hline Unassorted & \multicolumn{2}{|l|}{$224(37.5)$} \\
\hline \multicolumn{3}{|l|}{ Fecal occult blood\# } \\
\hline Positive & \multicolumn{2}{|l|}{ 129(33.9) } \\
\hline Negative & \multicolumn{2}{|l|}{$381(74.7)$} \\
\hline Combination of three regimens & \multicolumn{2}{|l|}{$217(36.3)$} \\
\hline Treatment response & \multicolumn{2}{|l|}{$N=312$} \\
\hline Partial response & \multicolumn{2}{|l|}{ 14(4.49) } \\
\hline Stable disease & 169(54.17) & \\
\hline Progressive disease & $129(41.35)$ & \\
\hline Tumor location & & \\
\hline Upper part $(U)$ & 253(42.3) & \\
\hline Middle part (M) & $91(15.2)$ & \\
\hline Lower part $(L)$ & 206(34.4) & \\
\hline$M L$ & $29(4.8)$ & \\
\hline MU & 19(3.2) & \\
\hline $\mathrm{T} / \mathrm{N}$ stage & & \\
\hline $\mathrm{la}+\mathrm{lb}$ & $4+7(6.5)$ & \\
\hline$\|\mathrm{a}+\| \mathrm{b}$ & $8+15(13.5)$ & \\
\hline$\||| a+|\|b+\|| \mid c$ & $34+46+56(80.0)$ & \\
\hline Hemoglobin level (g/L) & Initial & Post-treatment \\
\hline$>110$ & 398 & 327 \\
\hline $100-110$ & 78 & 91 \\
\hline $80-100$ & 82 & 124 \\
\hline $65-80$ & 26 & 41 \\
\hline$<65$ & 14 & 15 \\
\hline Manifestations of tumor hemorrhage & Initial & During treatment \\
\hline
\end{tabular}


Table 1 Patients characteristics (Continued)

\begin{tabular}{lll}
\hline & Total $N=598$ & 47 \\
\hline Fecal occult blood + & 37 & 76 \\
Erosion and bleeding by endoscopy & 92 & 40 \\
Hematemesis & 21 & 9 \\
Iron deficiency anemia & 3 & 136 \\
chemotherapy-induced anemia & 0 & 26 \\
Unknown & 50 & 5 \\
DIC & 0 & 4 \\
Bone marrow infiltration & 0 & \\
Chemo regimens & & 217 \\
DCF & 152 & 207 \\
FOLFIRl & 264 & \\
Paclitaxel liposome+Capecitabine/S-1 & 215 & \\
XP & & \\
Single agent
\end{tabular}

\# Fecal occult blood: 88 patients not testing at the date of diagnosis

metastases, paclitaxel-based combination of three regimens, the number of chemotherapy cycles, treatment response, and $\mathrm{HB}_{\mathrm{dec}} \geq 30 \mathrm{~g} / \mathrm{L}(p<0.05)$. Additionally, $\mathrm{HB}_{\mathrm{ini}}$ level, the lowest haemoglobin level, metastatic sites $\geq 3$, liver metastases, bone metastases, number of chemotherapy cycles, chemotherapy including paclitaxel, treatment response and $\mathrm{HB}_{\mathrm{dec}} \geq 30 \mathrm{~g} / \mathrm{L}$ were significantly associated with PFS $(p<0.05)$ (Table 4).

Multivariate analysis showed that $\mathrm{HB}_{\text {ini }}$ level $\leq 80 \mathrm{~g} / \mathrm{L}$ $(\mathrm{HR}=1.879,95 \% \mathrm{CI}=1.301-2.767, p=0.001)$, liver metastases $(\mathrm{HR}=1.234,95 \% \mathrm{CI}=1.022-1.490, p=0.029)$, chemotherapy including paclitaxel $(\mathrm{HR}=1.225,95 \% \mathrm{CI}=$ 1.013-1.481, $p=0.036)$, treatment response ( $\mathrm{HR}=1.457$, 95\% $\mathrm{CI}=1.173-1.808, \quad p=0.001)$, and $\mathrm{HB}_{\mathrm{dec}} \geq 30 \mathrm{~g} / \mathrm{L}$ $(\mathrm{HR}=1.536,95 \% \mathrm{CI}=1.206-1.957, p=0.001)$ were significant adverse prognosis factors of OS. More importantly, the number of chemotherapy cycles was also significantly correlated with improved $\mathrm{OS}(\mathrm{HR}=0.879$, 95\% CI $=0.855-0.904, p<0.001$ ) (Table 5).

For $\mathrm{PFS}, \mathrm{HB}_{\text {ini }}$ level $\leq 80 \mathrm{~g} / \mathrm{L} \quad(\mathrm{HR}=1.516,95 \% \mathrm{CI}=$ 1.082-2.126, $p=0.016$ ), chemotherapy including paclitaxel $\quad(\mathrm{HR}=1.273,95 \% \mathrm{CI}=1.068-1.517, \quad p=0.007)$, treatment response $(\mathrm{HR}=2.235,95 \% \mathrm{CI}=1.818-2.747$, $\mathrm{p}<0.001)$, the number of chemotherapy cycles $(\mathrm{HR}=$

Table 2 Clinical features which have potential effects on GC patient's OS and PFS

\begin{tabular}{llll}
\hline & $\mathrm{HB}_{\text {ini }} \leq 80 \mathrm{~g} / \mathrm{L}$ & $\mathrm{HB}_{\text {ini }}>80 \mathrm{~g} / \mathrm{L}$ & $p$ value \\
\hline Liver metastasis & 17 & 229 & 0.856 \\
Bone metastasis & 1 & 24 & 0.888 \\
Peritoneal metastasis & 1 & 66 & 0.122 \\
Lung metastasis & 5 & 94 & 0.475 \\
Metastatic sites $\geq 3$ & 11 & 116 & 0.316 \\
\hline
\end{tabular}

0.922, 95\% CI $=0.899-0.945, p<0.001)$, and $\mathrm{HB}_{\mathrm{dec}} \geq 30$ $\mathrm{g} / \mathrm{L}(\mathrm{HR}=1.543,95 \% \mathrm{CI}=1.233-1.932, p<0.001)$ were independent prognostic factors (Table 5).

To further determined the reason why chemotherapy including paclitaxel could influence the prognosis in our cohort patients, we analyzed the difference of clinical characteristics between patients who received chemotherapy including paclitaxel and those who did not. Our results revealed that the patients who received chemotherapy including paclitaxel were older than those who did not receive paclitaxel including chemotherapy in our cohort (Fig. 2) .

\section{Relationship between the degree of decrease in haemoglobin levels and the clinicopathological parameters of our patients}

We then investigated whether we could identify correlations between the degree of decrease in haemoglobin levels and the clinicopathological parameters of our GC patients. Our results suggested that bone metastases, chemotherapy including platinum, the number of chemotherapy cycles, and treatment response were associated with the degree of haemoglobin decrease $(p<$ $0.05)$ (Table 6). Multivariate analyses revealed that the degree of $\mathrm{HB}_{\mathrm{dec}}$ were significantly correlated with the number of chemotherapy cycles and chemotherapy including platinum $(p<0.001$ and $p=0.019$, respectively), and was not relevant with chemotherapy included paclitaxel (Table 7).

Chemotherapy drugs can not only kill cancer cells, but also damage healthy cells, which causes side effects. Our results revealed that the most common side effects of chemotherapy were myelosuppression, diarrhea and 

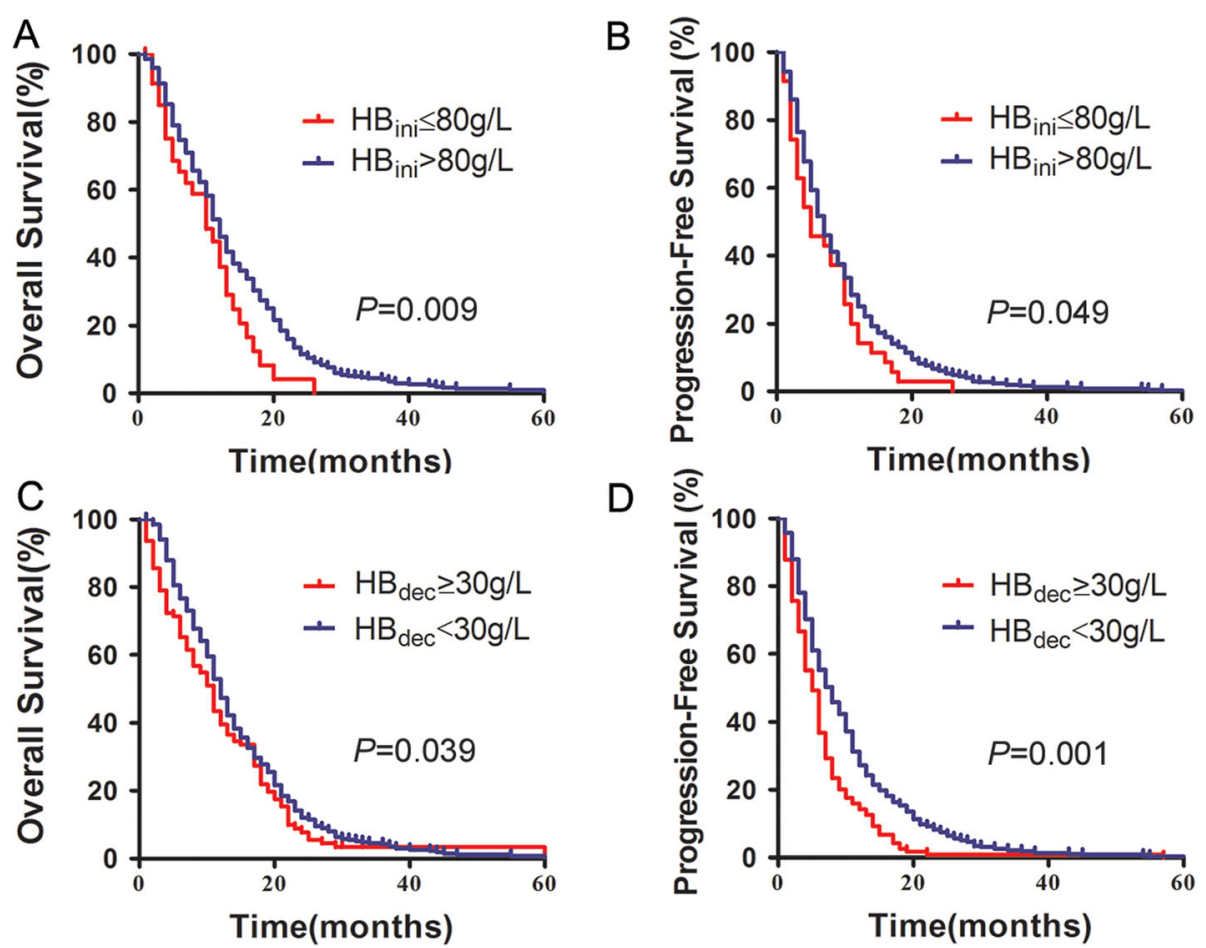

Fig. 1 The OS and PFS curves for 598 patients according to the degree of anaemia. a. OS curve according to HBini level (40 patients in the $H B_{\text {ini }} \leq 80 \mathrm{~g} / \mathrm{L}$ cohort and 558 patients in the $H B_{\text {ini }}$ level $>80 \mathrm{~g} / \mathrm{L}$ cohort); b. PFS curve according to $H B_{\text {ini }}$ level ( 40 patients in the $H B_{\text {ini }} \leq 80 \mathrm{~g} / \mathrm{L}$ cohort and 558 patients in the $\mathrm{HB}_{\text {ini }}$ level $>80 \mathrm{~g} / \mathrm{L}$ cohort); c. OS curve according to $\mathrm{HB}_{\text {dec }}$ ( 53 patients in the $\mathrm{HB}_{\text {dec }} \geq 30 \mathrm{~g} / \mathrm{L}$ cohort and 545 patients in the $\mathrm{HB}_{\text {dec }}<30 \mathrm{~g} / \mathrm{L}$ cohort); d. PFS curve according to $\mathrm{HB}_{\text {dec }}(\geq 30 \mathrm{~g} / \mathrm{L}$ and $<30 \mathrm{~g} / \mathrm{L}$ )

vomiting, yet which could not influence the OS and PFS in our cohort (Table 8).

\section{Discussion}

CRA occurs as a result of multiple aetiologies, including blood loss, functional iron deficiency, erythropoietin deficiency due to renal disease, chemotherapy-induced myelosuppression, marrow involvement with tumours and other factors. The relationship between anaemia and the prognosis of GC patients is rarely reported. Zhang et al. reported that patients with less than $\leq 65 \mathrm{~g} / \mathrm{L}$ haemoglobin had a significantly shorter median OS than patients with $65 \mathrm{~g} / \mathrm{L}$ to normal haemoglobin or patients with normal haemoglobin and demonstrated that a lower haemoglobin level might predict poorer OS in advanced GC patients
[15]. There is little information to evaluate the effect of anaemia status and RBC transfusion treatment on the OS and PFS of recurrent or metastatic GC patients.

According to the NCCN guidelines for cancer- and chemotherapy-induced anaemia, a haemoglobin level $\leq$ $80 \mathrm{~g} / \mathrm{L}$ is used to define severe-grade anaemia. Our present study also chose a haemoglobin level of $80 \mathrm{~g} / \mathrm{L}$ as the cut-off value for severe anaemia. Our results revealed that pretreatment of severe anaemia could serve as a prognostic factor in metastatic GC or recurrent GC patients who underwent radical resection and were then treated with chemotherapy. Multivariate analysis also showed that an initial haemoglobin level $\leq 80 \mathrm{~g} / \mathrm{L}$ was an independent adverse prognostic factor for our patients. In addition, the degree of haemoglobin decrease

Table 3 Median OS and PFS

\begin{tabular}{|c|c|c|c|c|c|c|}
\hline Variable & Median OS (m) & $95 \% \mathrm{Cl}$ & $p$ value & Median PFS (m) & $95 \% \mathrm{Cl}$ & $p$ value \\
\hline $\mathrm{HB}_{\text {ini }} \leq 80 \mathrm{~g} / \mathrm{L}$ & 10.0 & $6.147-13.853$ & 0.009 & 5.0 & $3.038-6.962$ & 0.049 \\
\hline$H B_{\text {ini }}>80 \mathrm{~g} / \mathrm{L}$ & 12.0 & $11.191-12.809$ & & 7.0 & $6.532-7.648$ & \\
\hline $\mathrm{HB}_{\mathrm{dec}} \geq 30 \mathrm{~g} / \mathrm{L}$ & 11.0 & 8.899-13.101 & 0.039 & 5.0 & $4.097-5.903$ & 0.001 \\
\hline $\mathrm{HB}_{\mathrm{dec}}<30 \mathrm{~g} / \mathrm{L}$ & 12.0 & $11.151-12.849$ & & 7.0 & $6.059-7.941$ & \\
\hline Transfusion yes & 12.0 & $9.436-14.564$ & 0.769 & 6.0 & $4.495-7.505$ & 0.468 \\
\hline Transfusion no & 12.0 & $11.185-12.815$ & & 7.0 & $6.266-7.734$ & \\
\hline
\end{tabular}


Table 4 Univariate analyses of risk factors for OS and PFS

\begin{tabular}{|c|c|c|c|c|c|c|c|}
\hline & $N=598$ & OS & & & PFS & & \\
\hline & & $p$ value & $\mathrm{HR}$ & $95 \% \mathrm{Cl}$ & $p$ value & $\mathrm{HR}$ & $95 \% \mathrm{Cl}$ \\
\hline $\mathrm{HB}_{\text {ini }}$ & & 0.010 & 0.995 & $0.991-0.999$ & 0.013 & 0.995 & $0.992-0.999$ \\
\hline$H B_{\text {lowest }}$ & & 0.575 & 0.999 & $0.995-1.003$ & 0.010 & 0.995 & $0.992-0.999$ \\
\hline $\mathrm{HB}_{\mathrm{ini}} \leq 80 \mathrm{~g} / \mathrm{L}$ & $40(6.7)$ & 0.012 & 1.608 & $1.109-2.332$ & 0.065 & 1.371 & $0.981-1.916$ \\
\hline$H B_{\text {ini }}>80 \mathrm{~g} / \mathrm{L}$ & 558(93.3) & & & & & & \\
\hline Metastases & & & & & & & \\
\hline Metastatic sites $\geq 3$ & $127(21.2)$ & 0.033 & 1.268 & $1.020-1.577$ & 0.015 & 1.289 & $1.050-1.583$ \\
\hline Metastatic sites $<3$ & $471(78.8)$ & & & & & & \\
\hline Lymph node & 457(76.4) & 0.849 & 0.980 & $0.794-1.209$ & 0.276 & 0.896 & $0.734-1.092$ \\
\hline Liver & $246(41.1)$ & 0.010 & 1.271 & $1.059-1.525$ & 0.001 & 1.354 & $1.141-1.607$ \\
\hline Lung & 99(16.6) & 0.399 & 0.899 & $0.703-1.151$ & 0.221 & 1.150 & $0.920-1.438$ \\
\hline Bone & $25(4.2)$ & 0.072 & 1.495 & $0.964-2.318$ & 0.017 & 1.651 & $1.093-2.493$ \\
\hline Peritoneum & $67(11.20)$ & 0.181 & 0.821 & $0.651-1.096$ & 0.771 & 0.960 & $0.729-1.264$ \\
\hline Chemotherapy regimen & & & & & & & \\
\hline Included paclitaxel & $239(40.0)$ & 0.116 & 1.160 & $0.964-1.397$ & 0.018 & 1.232 & $1.037-1.463$ \\
\hline Included platinum & $61(10.2)$ & 0.290 & 0.849 & $0.626-1.150$ & 0.734 & 0.985 & $0.748-1.296$ \\
\hline Number of cycles & & $<0.001$ & 0.916 & $0.894-0.940$ & 0.006 & 0.97 & $0.948-0.991$ \\
\hline Number of PTX3* & & 0.023 & 0.937 & $0.885-0.991$ & 0.940 & 1.002 & $0.955-1.051$ \\
\hline Treatment response & & & & & & & \\
\hline Progressive disease & 188(31.4) & 0.041 & 1.223 & $1.008-1.484$ & $<0.001$ & 1.959 & $1.634-2.350$ \\
\hline Non-progressive disease & $410(68.6)$ & & & & & & \\
\hline$H B_{\text {dec }}$ & & & & & & & \\
\hline$\geq 30$ & $131(21.9)$ & 0.048 & 1.244 & $1.002-1.546$ & $<0.001$ & 1.594 & $1.302-1.951$ \\
\hline$<30$ & $467(78.1)$ & & & & & & \\
\hline Transfusion & $87(14.5)$ & 0.778 & 1.038 & $0.802-1.342$ & 0.492 & 1.085 & $0.860-1.367$ \\
\hline No transfusion & $511(85.5)$ & & & & & & \\
\hline Adjuvant chemotherapy & 170 & 0.735 & 1.010 & $0.954-1.070$ & 0.470 & 0.981 & $0.931-1.034$ \\
\hline
\end{tabular}

*PTX3 paclitaxel-based combination of three regimens

Table 5 Multivariate analyses of risk factors for OS and PFS

\begin{tabular}{|c|c|c|c|c|c|c|}
\hline & OS & & & PFS & & \\
\hline & $p$ value & $H R$ & $95 \% \mathrm{Cl}$ & $p$ value & $\mathrm{HR}$ & $95 \% \mathrm{Cl}$ \\
\hline$H B_{\text {ini }} \leq 80 \mathrm{~g} / \mathrm{L}$ & 0.001 & 1.879 & $1.301-2.767$ & 0.016 & 1.516 & $1.082-2.126$ \\
\hline metastatic sites $\geq 3$ & 0.063 & 1.246 & $0.989-1.572$ & 0.823 & 1.026 & $0.821-1.281$ \\
\hline Liver metastases & 0.029 & 1.234 & $1.022-1.490$ & 0.057 & 1.188 & $0.885-1.420$ \\
\hline Bone metastases & 0.269 & 1.293 & $0.820-2.040$ & 0.685 & 1.094 & $0.709-1.689$ \\
\hline Chemotherapy included paclitaxel & 0.036 & 1.225 & $1.013-1.481$ & 0.007 & 1.273 & $1.068-1.517$ \\
\hline Number of cycles & $<0.001$ & 0.879 & $0.855-0.904$ & $<0.001$ & 0.922 & $0.899-0.945$ \\
\hline Treatment response & 0.001 & 1.457 & $1.173-1.808$ & $<0.001$ & 2.235 & $1.818-2.747$ \\
\hline $\mathrm{HB}_{\mathrm{dec}} \geq 30 \mathrm{~g} / \mathrm{L}$ & 0.001 & 1.536 & $1.206-1.957$ & $<0.001$ & 1.543 & $1.233-1.932$ \\
\hline
\end{tabular}




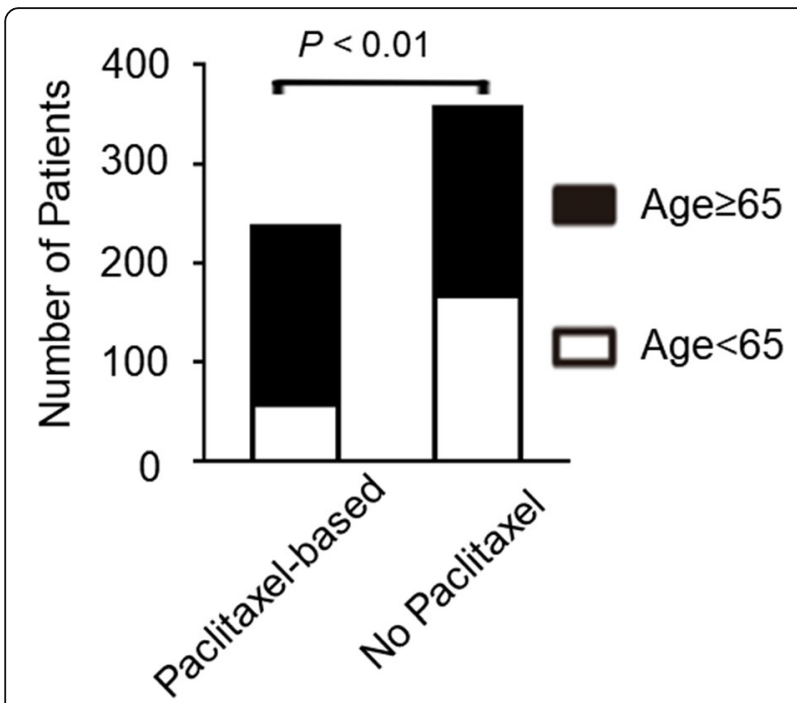

Fig. 2 Patients who received paclitaxel-based chemotherapy were older than those who did not receive paclitaxel

(haemoglobin level $\geq 30 \mathrm{~g} / \mathrm{L}$ ) during chemotherapy or the follow-up period was also an important risk factor for the prognosis of recurrent or metastatic GC.

The cause of anaemia in patients with cancer is often multifactorial. The malignancy itself can lead to or exacerbate anaemia, and underlying comorbidities may also contribute to anaemia. Cancer cells can directly suppress haematopoiesis through bone marrow infiltration and produce cytokines, leading to iron sequestration. Chronic blood loss, nutritional deficiencies, myelosuppressive effects of chemotherapy, and radiation therapy to the

Table 6 Univariate analyses of risk factors for $\mathrm{HB}_{\mathrm{dec}}$

\begin{tabular}{llll}
\hline & $p$ value & $\mathrm{HR}$ & $95 \% \mathrm{Cl}$ \\
\hline $\begin{array}{l}\text { Metastases } \\
\text { metastatic sites } \geq 3\end{array}$ & 0.141 & 0.838 & $0.663-1.060$ \\
$\begin{array}{l}\text { metastatic sites }<3 \\
\text { Metastatic site }\end{array}$ & & & \\
$\quad$ Lymph node & 0.325 & 1.131 & $0.885-1.444$ \\
$\quad$ Liver & 0.328 & 1.107 & $0.903-1.358$ \\
Lung & 0.936 & 0.989 & $0.763-1.283$ \\
$\quad$ Bone & 0.017 & 0.574 & $0.365-0.905$ \\
Chemotherapy regimen & & & \\
$\quad$ Included paclitaxel & 0.876 & 0.984 & $0.802-1.207$ \\
$\quad$ Included platinum & 0.010 & 0.645 & $0.463-0.899$ \\
Number of cycles & $<0.001$ & 0.933 & $0.907-0.961$ \\
Number of PTX3 & 0.161 & 0.96 & $0.908-1.016$ \\
Treatment response & & & \\
$\quad$ Progressive disease & 0.037 & 0.798 & $0.646-0.986$ \\
$\quad$ Non-progressive disease & & & \\
\hline
\end{tabular}

Table 7 Multivariate analyses of risk factors for $\mathrm{HB}_{\mathrm{dec}}$

\begin{tabular}{llll}
\hline Variable & $p$ value & $\mathrm{HR}$ & $95 \% \mathrm{Cl}$ \\
\hline Chemotherapy included platinum & 0.019 & 0.661 & $0.468-0.934$ \\
Metastatic sites $\geq 3$ & 0.371 & 0.895 & $0.702-1.141$ \\
Bone metastases & 0.055 & 0.633 & $0.396-1.010$ \\
Chemotherapy included paclitaxel & 0.061 & 1.226 & $0.991-1.517$ \\
Number of chemotherapy cycles & $<0.001$ & 0.938 & $0.911-0.966$ \\
Liver metastases & 0.060 & 1.227 & $0.991-1.520$ \\
Treatment response & 0.111 & 0.833 & $0.665-1.043$ \\
\hline
\end{tabular}

skeleton can further exacerbate anaemia in patients with cancer [6-10]. Due to the potentially multifactorial complexity of anaemia, defining the causes of anaemia in cancer patients is essential, which will contribute to determining the appropriate treatment method to apply.

Previous researches recognized paclitaxel as first- or second-line chemotherapy, in which median overall survival was several months $[16,17]$. Our study revealed that paclitaxel was an independent adverse prognostic factor, but was not relevant with the degree of $\mathrm{HB}_{\mathrm{dec}}$. Our results were also different with previous research which showed that docetaxel, a newly taxoid anticancer drug, can cause a progression in anaemia from grade III to IV in $9 \%$ of patients [18]. The reasons for those results may be related with the proportion of elderly patients. Thus, the role of paclitaxel in influencing the prognosis and HB level of the GC patient needs for further assessment.

To the contrary, our results showed that chemotherapy including platinum was associated with a decrease in haemoglobin in recurrent or metastatic GC patients, which are similar to the findings of previous reports. Groopman et al. reported that platinum-based regimens are well known to induce anaemia due to the combined bone marrow and kidney toxicity, and the use of chemotherapy regimens including paclitaxel is an adverse prognostic factor for decreased haemoglobin, although this effect is not significant [19]. Therefore, we consider that platinum should not be recommended to treat severely anaemic recurrent or metastatic GC patients until the anaemia has been improved through treatment. The other regimens such as capecitabine can be chose to treat the severely anaemic GC patients.

The most common treatment options for CRA include erythropoietic-stimulating agents, RBC transfusion and nutritional therapy, such as iron intake. Previous studies have reported that the lowest postoperative haemoglobin level and postoperative transfusion were the most significant risk factors for postoperative complications in GC surgery [20]. Squires et al. reported that perioperative allogeneic blood transfusion was associated with decreased PFS and OS after resection of GC, independent of adverse clinicopathologic factors [21]. In addition, 
Table 8 Univariate analyses of chemotherapy side effects for OS and PFS

\begin{tabular}{|c|c|c|c|c|c|c|c|}
\hline & \multirow{2}{*}{$\begin{array}{l}N= \\
598\end{array}$} & \multicolumn{3}{|l|}{ OS } & \multicolumn{3}{|l|}{ PFS } \\
\hline & & $p$ value & $H R$ & $95 \% \mathrm{Cl}$ & $p$ value & $\mathrm{HR}$ & $95 \% \mathrm{Cl}$ \\
\hline \multicolumn{8}{|c|}{ Myelosupression } \\
\hline Degree I & 103 & 0.001 & 3.117 & $1.809-4.371$ & 0.148 & 1.47 & $0.872-2.48$ \\
\hline Degree II & 137 & 0.075 & 1.371 & $0.911-2.943$ & 0.598 & 1.157 & $0.372-1.993$ \\
\hline Degree III & 63 & 0.102 & 1.591 & $0.911-2.776$ & 0.680 & 1.119 & $0.656-1.909$ \\
\hline Degree IV & 15 & 0.998 & 1.001 & $0.552-1.814$ & 0.600 & 0.860 & $0.489-1.512$ \\
\hline \multicolumn{8}{|l|}{ Diarrhea } \\
\hline Grade1 & 519 & & & & & & \\
\hline Grade2 & 52 & 0.196 & 0.757 & $0.496-1.155$ & 0.227 & 0.787 & $0.533-1.161$ \\
\hline Grade3 & 27 & 0.045 & 0.580 & $0.40-0.989$ & 0.313 & 0.785 & $0.490-1.256$ \\
\hline \multicolumn{8}{|l|}{ Vomiting } \\
\hline Grade1 & 136 & & & & & & \\
\hline Grade 2 & 443 & 0.189 & 0.702 & $0.414-1.190$ & 0.738 & 0.917 & $0.553-1.521$ \\
\hline Grade 3 & 19 & 0.213 & 0.727 & $0.440-1.201$ & 0.252 & 0.752 & $0.462-1.225$ \\
\hline
\end{tabular}

RBC transfusion could not improve the chemotherapy outcomes by increasing the haemoglobin level [22]. However, the role of $\mathrm{RBC}$ transfusion in improving the prognosis of recurrent or metastatic GC patients remains unclear. Our present data support the notion that transfusion neither significantly improved the OS and PFS nor served as a risk factor for PFS and OS in recurrent or metastatic GC. These results may be attributed to the fact that transfusion was used only when haemoglobin was not more than $70 \mathrm{~g} / \mathrm{L}$ in our hospital. Insufficient blood transfusion may be another possible reason for this result.

However, our study also has several limitations. First, our study is a retrospective analysis, so our results should be confirmed by multicenter-randomized trials. Second, the inequality in the number of patients enrolled in our different cohorts can also generate potential bias. Third, high proportion of patients $(286 / 598,47.8 \%)$ only received 1-2 cycles of chemotherapy treatment, which can also influence the treatment effect of chemotherapy.

\section{Conclusions}

Our study demonstrated that the initial degree of anaemia can serve as a biomarker for predicting the prognosis of recurrent or metastatic GC patients, while chemotherapy treatment rather than $\mathrm{RBC}$ transfusion can improve OS and PFS. In addition, platinum should not be recommended to treat severely anaemic GC patients.

\section{Supplementary information}

Supplementary information accompanies this paper at https://doi.org/10. 1186/s12885-020-06881-7.

Additional file 1 Table S1. Median OS and PFS

\section{Abbreviations}

GC: Gastric cancer; CRA: Cancer-related anaemia; ECOG PS: The Eastern Cooperative Oncology Group performance score; $\mathrm{HB}_{\text {ini: }}$ : The initial haemoglobin level; $\mathrm{HB}_{\text {dec: }}$ : The decrease of haemoglobin; NCCN: National Comprehensive Cancer Network; DCF: Docetaxel, cisplatin, and 5-fluorouracil; BID: Twice daily; RECIST: Response Evaluation Criteria in Solid Tumors; OS: Overall survival; PFS: Progression-free survival; HRs: Hazard ratios; RBC, Red blood cell

\section{Acknowledgements}

Not applicable.

\section{Authors' contributions}

WH $L$ conceived the study. WH $L$ and $X X C$ made substantial contributions to data acquisition, $W H L, J Y Z, W H L$ and $X X C$ performed measurements, analyzed the data and drafted the manuscript. All authors have read and approved the final manuscript.

\section{Funding}

This study was supported by Shandong Key Research and Development Plan (2019GSF108219). The fund mentioned was used for the design of the study, the collection, analysis, and interpretation of the data as well as the writing of the manuscript. The funder of the Shandong Key Research and Development Plan (2019GSF108219) is Wenhuan Li who is responsible for designing and performing this study.

Availability of data and materials

The datasets used and/or analyzed during the current study available from the corresponding author on reasonable request.

\section{Ethics approval and consent to participate}

Written informed consent was obtained from each participant before the sample collection. The study was approved by the ethical committee of Shandong Provincial Hospital and was performed according to the declaration of Helsinki.

Consent for publication

Not applicable.

\section{Competing interests}

The authors declare no conflict of interest. There are no financial and nonfinancial competing interests (political, personal, religious, ideological, academic, intellectual, commercial or any other) to declare in relation to this manuscript. 


\section{Author details}

1Department of Oncology, Shandong Provincial Hospital Affiliated to Shandong University, 324 Jingwu RD, Jinan 250021, Shandong, People's Republic of China. ${ }^{2}$ Shandong Center for Diseases Control and Prevention, 16992 Jingshi RD, Jinan 250014, Shandong, People's Republic of China. ${ }^{3}$ School of Public Health, Shandong University, Jinan 250012, Shandong, People's Republic of China.

Received: 6 June 2019 Accepted: 21 April 2020

Published online: 13 May 2020

\section{References}

1. Meric-Bernstam F, Johnson AM, Dumbrava EEl, et al. Advances in HER2Targeted Therapy: Novel Agents and Opportunities Beyond Breast and Gastric Cancer. Clin Cancer Res. 2019;25(7):2033-41.

2. Huang L, Wu RL, Xu AM. Epithelial-mesenchymal transition in gastric cancer. Am J Transl Res. 2015;7(11):2141-58.

3. Dong XF, Liu TQ, Zhi XT, et al. COX-2/PGE2 Axis Regulates HIF2a Activity to Promote Hepatocellular Carcinoma Hypoxic Response and Reduce the Sensitivity of Sorafenib Treatment. Clin Cancer Res. 2018;24(13):3204-16.

4. Hironaka S, Ueda S, Yasui H, et al. Randomized, open-label, phase III study comparing irinotecan with paclitaxel in patients with advanced gastric cancer without severe peritoneal metastasis after failure of prior combination chemotherapy using fluoropyrimidine plus platinum: WJOG 4007 trial. J Clin Oncol. 2013;31:4438-44.

5. Hironaka S, Sugimoto N, Yamaguchi K, et al. S-1 plus leucovorin versus S-1 plus leucovorin and oxaliplatin versus S-1 plus cisplatin in patients with advanced gastric cancer: a randomized, multicenter, open-label, phase 2 trial. Lancet Oncol. 2016;17:99-108.

6. Gilreath JA, Stenehjem DD, Rodgers GM. Diagnosis and treatment of cancer-related anemia. Am J Hematol. 2014;89(2):203-12.

7. Pham CM, Syed AA, Siddiqui HA, et al. Case of metastatic basal cell carcinoma to bone marrow, resulting in myelophthisic anemia. Am J Dermatopathol. 2013;35(2):e34-6.

8. Kamei A, Gao G, Neale G, et al. Exogenous remodeling of lung resident macrophages protects against infectious consequences of bone marrowsuppressive chemotherapy. Proc Natl Acad Sci U S A. 2016;113(41):E6153-61.

9. Chant C, Wilson G, Friedrich JO. Anemia, transfusion, and phlebotomy practices in critically ill patients with prolonged ICU length of stay: a cohort study. Crit Care. 2006;10(5):R140.

10. Aapro M, Jelkmann W, Constantinescu SN, et al. Effects of erythropoietin receptors and erythropoiesis-stimulating agents on disease progression in cancer. Br J Cancer. 2012;106(7):1249-58.

11. Manig L, Käsmann L, Janssen S, et al. Simplified comorbidity score and eastern cooperative oncology group performance score predicts survival in patients receiving organ-preserving treatment for bladder Cancer. Anticancer Res. 2017;37(5):2693-6.

12. Ettinger DS, Kuettel M, Malin J, et al. NCCN roundtable: what are the characteristics of an optimal clinical practice guideline? I Natl Compr Cancer Netw. 2015;13(5 Suppl):640-2.

13. Nishino $M$, Jackman DM, Hatabu $H$, et al. New response evaluation criteria in solid tumors (RECIST) guidelines for advanced non-small cell lung cancer: comparison with original RECIST and impact on assessment of tumor response to targeted therapy. AJR Am J Roentgenol. 2010;195(3):W221-8.

14. Ock CY, Oh DY, Lee J, et al. Weight loss at the first month of palliative chemotherapy predicts survival outcomes in patients with advanced gastric cancer. Gastric Cancer. 2016;19:597-606.

15. Zhang S, Lu M, Li Y, et al. A lower haemoglobin level predicts a worse survival of patients with advanced gastric cancer. Clin Oncol. 2014;26:239-40.

16. Hironaka S, Zenda S, Boku N, et al. Weekly paclitaxel as second-line chemotherapy for advanced or recurrent gastric cancer. Gastric Cancer. 2006;9(1):14-8.

17. Ajani JA, Fodor MB, Tjulandin SA, et al. Phase II multi-institutional randomized trial of docetaxel plus cisplatin with or without fluorouracil in patients with untreated, advanced gastric, or gastroesophageal adenocarcinoma. J Clin Oncol. 2005;23(24):5660-7.

18. Posner MR, Lefebvre JL. Docetaxel induction therapy in locally advanced squamous cell carcinoma of the head and neck. Br J Cancer. 2003;88(1):11-7.

19. Groopman JE, Itri LM. Chemotherapy-induced anemia in adults: incidence and treatment. J Natl Cancer Inst. 1999;91:1616-34.
20. Jung DH, Lee HJ, Han DS, et al. Impact of perioperative hemoglobin levels on postoperative outcomes in gastric cancer surgery. Gastric Cancer. 2013; 16:377-82.

21. Squires MH, Kooby DA, Poultsides GA, et al. Effect of perioperative transfusion on recurrence and survival after gastric cancer resection: a 7institution analysis of 765 patients from the US gastric cancer collaborative. J Am Coll Surg. 2015;22:767-77.

22. Ye $X, L i u J$, Chen $Y$, et al. The impact of hemoglobin level and transfusion on the outcomes of chemotherapy in gastric cancer patients. Int J Clin Exp Med. 2015;8(3):4228-35.

\section{Publisher's Note}

Springer Nature remains neutral with regard to jurisdictional claims in published maps and institutional affiliations.

\section{Ready to submit your research? Choose BMC and benefit from:}

- fast, convenient online submission

- thorough peer review by experienced researchers in your field

- rapid publication on acceptance

- support for research data, including large and complex data types

- gold Open Access which fosters wider collaboration and increased citations

- maximum visibility for your research: over $100 \mathrm{M}$ website views per year

At BMC, research is always in progress.

Learn more biomedcentral.com/submissions 